\title{
Additive Manufacturing of Thermoset Cellular Structures
}

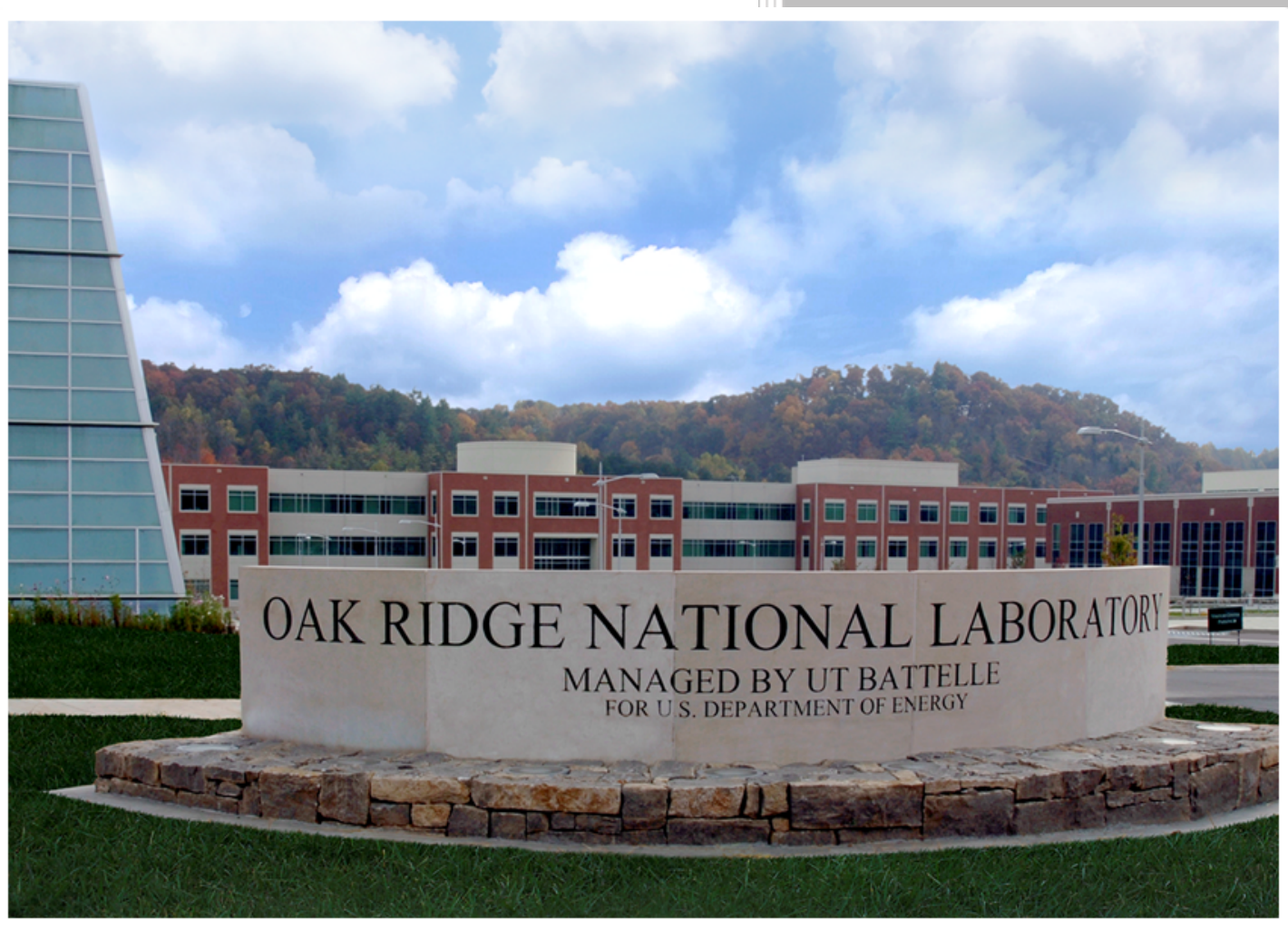

Vlastimil Kunc

April 15, 2019

CRADA FINAL REPORT

NFE-17-06578

Approved for Public Release. Distribution is Unlimited. 


\section{DOCUMENT AVAILABILITY}

Reports produced after January 1, 1996, are generally available free via US Department of Energy (DOE) SciTech Connect.

Website http://www.osti.gov/scitech/

Reports produced before January 1, 1996, may be purchased by members of the public from the following source:

National Technical Information Service
5285 Port Royal Road
Springfield, VA 22161
Telephone 703-605-6000 (1-800-553-6847)
TDD 703-487-4639
Fax 703-605-6900
E-mail info@ntis.gov
Website http://www.ntis.gov/help/ordermethods.aspx

Reports are available to DOE employees, DOE contractors, Energy Technology Data Exchange representatives, and International Nuclear Information System representatives from the following source:

Office of Scientific and Technical Information

PO Box 62

Oak Ridge, TN 37831

Telephone 865-576-8401

Fax 865-576-5728

E-mail reports@osti.gov

Website http://www.osti.gov/contact.html

This report was prepared as an account of work sponsored by an agency of the United States Government. Neither the United States Government nor any agency thereof, nor any of their employees, makes any warranty, express or implied, or assumes any legal liability or responsibility for the accuracy, completeness, or usefulness of any information, apparatus, product, or process disclosed, or represents that its use would not infringe privately owned rights. Reference herein to any specific commercial product, process, or service by trade name, trademark, manufacturer, or otherwise, does not necessarily constitute or imply its endorsement, recommendation, or favoring by the United States Government or any agency thereof. The views and opinions of authors expressed herein do not necessarily state or reflect those of the United States Government or any agency thereof. 
ORNL/TM-2019/1165

CRADA/NFE-17-06578

Energy and Transportation Sciences Division

Advanced Manufacturing Office

\title{
Additive Manufacturing of Thermoset Cellular Structures
}

\author{
Authors \\ Vlastimil Kunc \\ John Lindahl \\ Christopher Hershey \\ Mike Kastura \\ Mike Walch \\ Tim De-Luca
}

Date Published:

April 15, 2019

\author{
Prepared by \\ OAK RIDGE NATIONAL LABORATORY \\ Oak Ridge, Tennessee 37831-6283 \\ managed by \\ UT-BATTELLE, LLC \\ for the \\ US DEPARTMENT OF ENERGY \\ under contract DE-AC05-00OR22725
}

Approved For Public Release 



\section{CONTENTS}

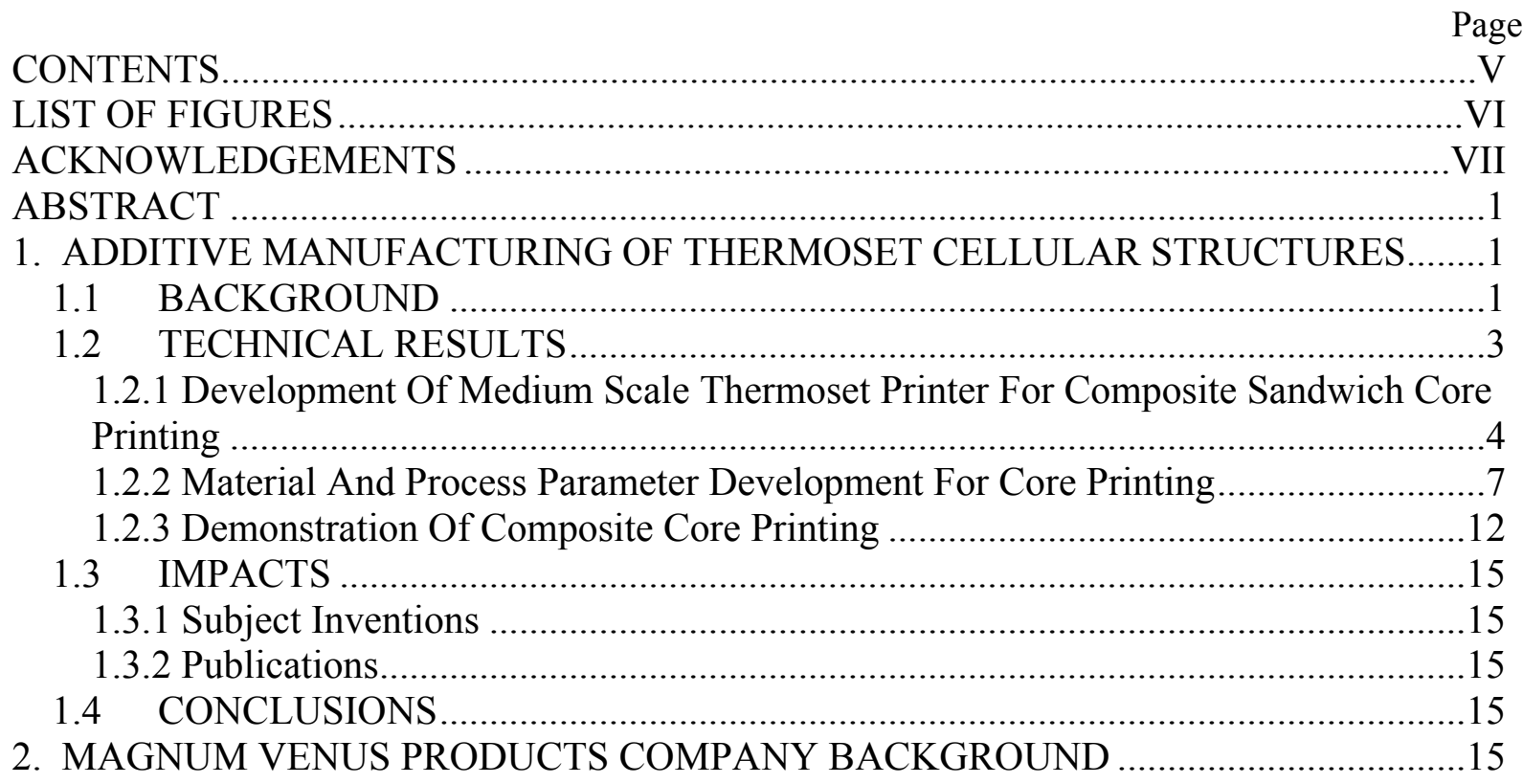




\section{LIST OF FIGURES}

Figure 1. Desktop thermoset printer (left), 3D printed epoxy cellular structure (right).

Figure 2.3D printed thermoset honeycomb core with variable density (left), typical uniform honeycomb (right).

Figure 3. Outside view printer with enclosures in place and ventilation exhaust tubing. $\quad 4$

Figure 4. Downdraft system to be installed around the perimeter of the printer. 5

Figure 5. Thermoset printer shipped from Kent, WA, to Knoxville, TN 5

Figure 6. Installation of thermoset printer at the Manufacturing Demonstration Facility of ORNL.

Figure 7. Downdraft system and rollers for a removable bed.

Figure 8. Final configuration of printer gantry and loading station. $\quad 7$

Figure 9. Ribbon cutting ceremony for thermoset printer at ORNL.

Figure 10. Permanently installed infrared camera. $\quad 8$

Figure 11. Infrared image shows exotherm in deposited material. $\quad 8$

Figure 12. MVP printer enclosure, light curtain and fume isolation. $\quad 9$

Figure 13. MVP printer loading area enclosure and ventilation. $\quad 9$

Figure 14. Initial print test of multi-layer hexagon. 10

Figure 15. Print test of a square with rectangular lattice infill. $\quad 10$

Figure 16. Progressive curing of thermoset material during printing. 11

Figure 17. Large volume hexagon printed with long gel time material. 11

Figure 18. Infrared image of thermoset material deposition showing elevated temperature of reacting polymer. $\quad 12$

Figure 19. Example variable density lattice printed during material development. 12

Figure 20. Variable density lattice structure printed on MVP machine. 13

Figure 21. CAMX booth display. $\quad 14$

Figure 22. Award for Composites Excellence booth. 14

Figure 23. Car hood with thermoset 3D printed variable density core. 15 


\section{ACKNOWLEDGEMENTS}

This CRADA NFE-17-06578 was conducted as an EERE Technology Commercialization Fund project within the Oak Ridge National Laboratory (ORNL) Manufacturing Demonstration Facility (MDF) sponsored by the US Department of Energy Advanced Manufacturing Office (CPS Agreement Number 32144). Research sponsored by the U.S. Department of Energy, Office of Energy Efficiency and Renewable Energy, Advanced Manufacturing Office, under contract DE-AC0500OR22725 with UT-Battelle, LLC. 


\begin{abstract}
Magnum Venus Products (MVP) and Oak Ridge National Laboratory (ORNL) set out to develop and commercialize a 3D printer depositing thermoset polymers with a build volume accommodating mid-scale applications capable of deposition rate exceeding $10 \mathrm{lb} / \mathrm{hr}$ with resolution of $3 \mathrm{~mm}$ or less. The objective of this work was to demonstrate the ability to efficiently print light weight cellular structures for application in load bearing structural applications, thereby transforming the mid to large scale additive technology. The project was organized around three main tasks: 1 . Thermoset printer development, 2. Material and process parameter development and 3. Demonstration. The MVP-ORNL team successfully carried out the project by creating the first thermoset 3D printer of this size in the world and by using it to demonstrate the ability to print cellular structures. The team was awarded the Award for Composites Excellence at the 2018 CAMX conference for this development.
\end{abstract}

\title{
1. ADDITIVE MANUFACTURING OF THERMOSET CELLULAR STRUCTURES
}

This is an EERE Technology Commercialization Fund project. In this final report, we detail background, technology development, demonstration and impact of our work.

\subsection{BACKGROUND}

Polymer additive manufacturing and 3D printing are currently used primarily for nonstructural or semi-structural applications. Aside from prototyping and shape demonstrations, the technology is used in the industry for manufacture of custom jigs, fixtures and tools where only material stiffness is required to satisfy most application requirements. As soon as a printed structure has to carry significant load, the strength of the interface between layers limits the use of AM parts made with thermoplastic materials. Thermoset layered manufacturing can alleviate this problem by using polymers that will fully cross-link between layers, and not rely on partial fusion of polymer chains as in the case of thermoplastic printers. Additionally, most thermoset materials can be printed at room temperature or at slightly elevated temperature, which will reduce thermally induced residual stresses and deformations. Reaction induced deformations will be present in a printed thermoset structure, however residual stresses will be much lower as the stresses will not build sequentially with deposition of every layer.

ORNL developed the capability to print thermosets on small scale and demonstrated the ability to print thin wall cellular structures suitable for use in composite sandwich structures (see Figure 1). 

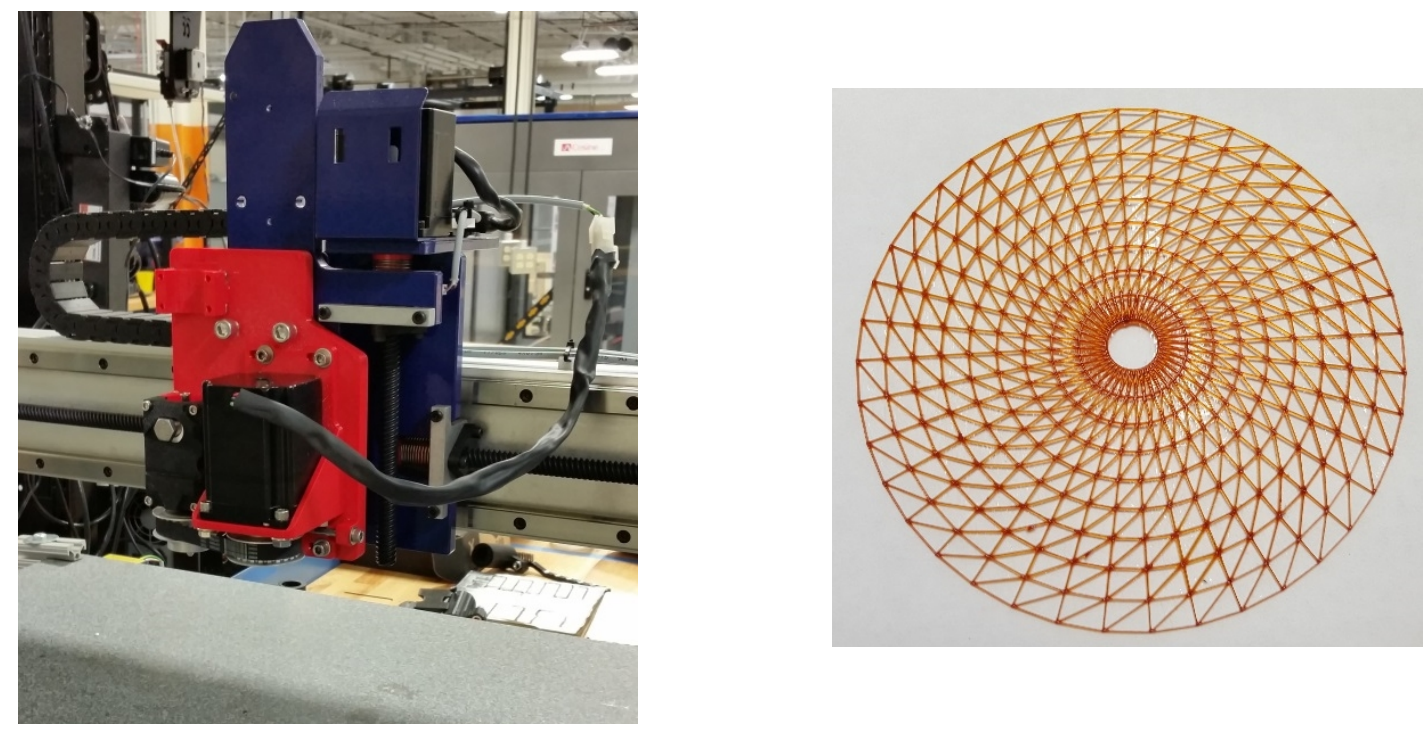

Figure 1. Desktop thermoset printer (left), 3D printed epoxy cellular structure (right).

The power of this technology can be realized by printing cellular cores for sandwich structures, examples shown in Figure 2.
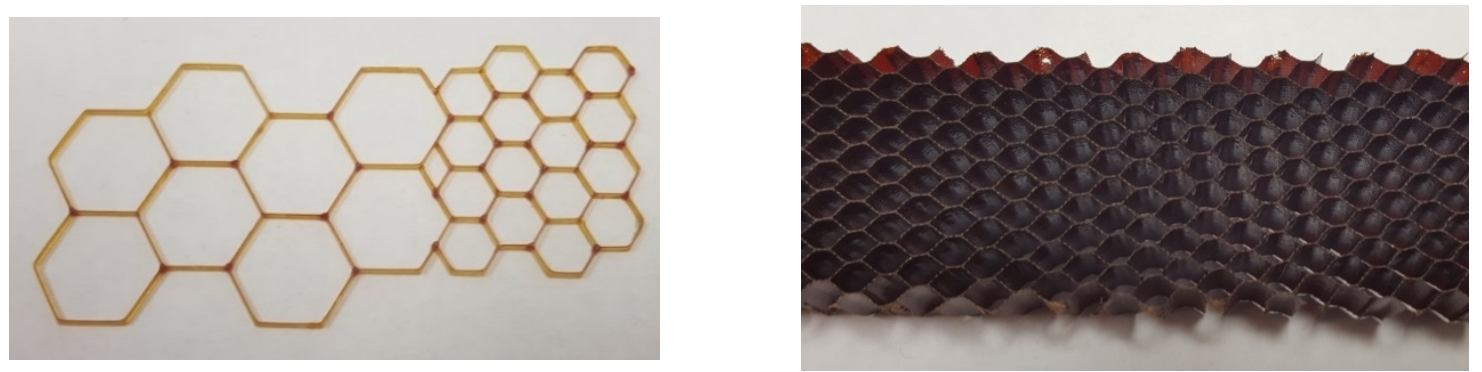

Figure 2. 3D printed thermoset honeycomb core with variable density (left), typical uniform honeycomb (right).

Sandwich structures typically consist of two load bearing skins and a lightweight core. The skins are typically made of fiber reinforced composite or aluminum sheet. However, the core is a foam or honeycomb structure that is made usually of impregnated paper, plastic sheets or aluminum sheets. The main function of the core is to transfer moderate load between skins in compression and shear modes. The honeycomb density is currently sized to accommodate the highest load experienced by the structure as the current technologies are limited to fabricate only uniform density honeycombs and joining of these sheets is difficult and time consuming. Additive manufacturing can uniquely and effectively addresses these limitations by printing variable density cellular structures tailored for each individual application, as shown in Figure 2. The technology presented in this report will generate lighter structures and consume less material, resulting in energy and cost savings for both manufacturers and end users. In addition, 3D printing cellular structures for applications other than sandwich cores will result in faster prints and lighter parts. 
The project was organized into four tasks:

Task 1. Development of medium scale thermoset printer for composite sandwich core printing

Task 1 focused on development of 6 X 6 X 6 foot to $12 \times 12 \times 6$ foot, four-axis gantry with integrated resin delivery system. To maximize commercial impact, the gantry is sized to accommodate generic AM builds, while only limited build height is needed for the specific application of sandwich core cellular structure printing. There are three subtasks.

Task 1.1 Development of four axis gantry (MVP lead with ORNL providing requirements)

Task 1.2 Development of delivery system (MVP lead)

Task 1.3 Integration of resin delivery equipment with gantry (MVP lead with ORNL support)

Task 2. Material and process parameter development for core printing In this task, material suitable for 3D printing of lightweight sandwich cores were selected. The material of choice was suitable for deposition at high rates with high resolution. While the printer developed in this project is capable of producing generic 3D printed structures, the material targeted only specific application of cellular sandwich cores with limited height requirement. There are two subtasks.

Task 2.1 Material selection (ORNL lead)

Task 2.2 Delivery system modification (ORNL lead with MVP support)

Task 3. Demonstration of composite core printing

The team selected public forum in which an article printed with this technology was demonstrated. This forum was intended to be a major conference, organized event or a workshop. Based on target audience of this event, the demonstration article was selected and designed. There are three subtasks.

Task 3.1 Demonstration article selection (MVP and ORNL)

Task 3.2 Demonstration article manufacture (ORNL lead)

Task 3.3 Public forum demonstration (MVP lead)

Task 4. Project management and reporting

The team held bi-weekly conference calls and provided information to the sponsor on progress and financials of the project quarterly.

\subsection{TECHNICAL RESULTS}

In this section, we will discuss technical developments according to tasks outlined above. The tasks were executed concurrently as machine development and material properties of printed substances are interdependent. 


\subsubsection{Development of medium scale thermoset printer for composite sandwich core printing}

The team has leveraged previous work in thermoset additive manufacturing to estimate the properties of materials that would be used in the newly developed printer. Additionally, lessons learned from operation of large scale printers guided design choices for the thermoset printer. Significant effort was expended on safety analysis and preparation of printing of large thermoset structures. Compared to existing large format thermoplastic printers, this thermoset printer handles reactive polymers and potentially significant amount of volatiles. To this end, ventilation system was designed as shown in Figure 3 and Figure 4. Figure 3 shows the final concept of the printer with enclosures in place and exhaust tubing designed to lead volatiles to a ceiling facility fan. Figure 4 shows the internal configuration of the downdraft system to be installed within the printer.

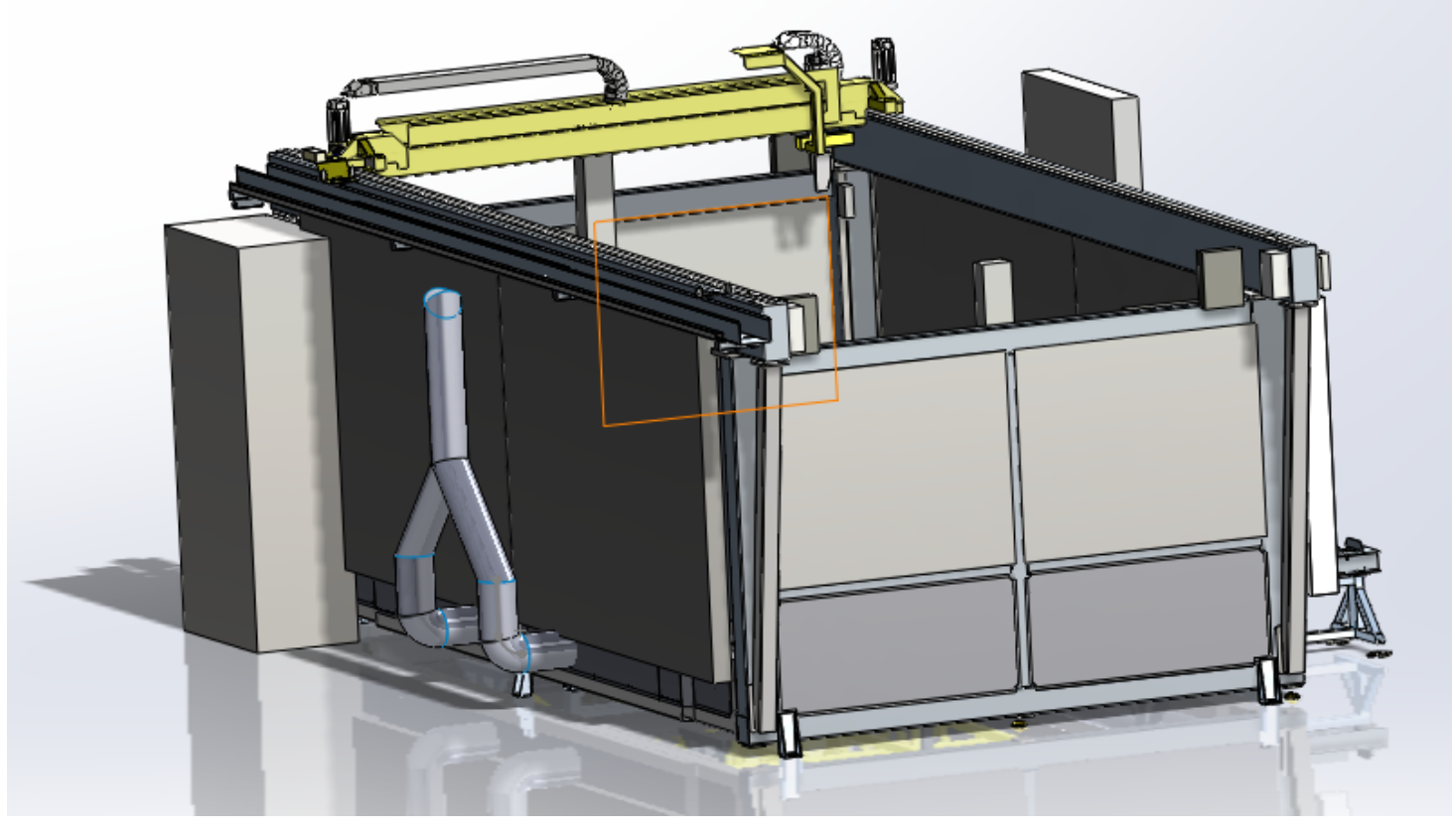

Figure 3. Outside view printer with enclosures in place and ventilation exhaust tubing. 


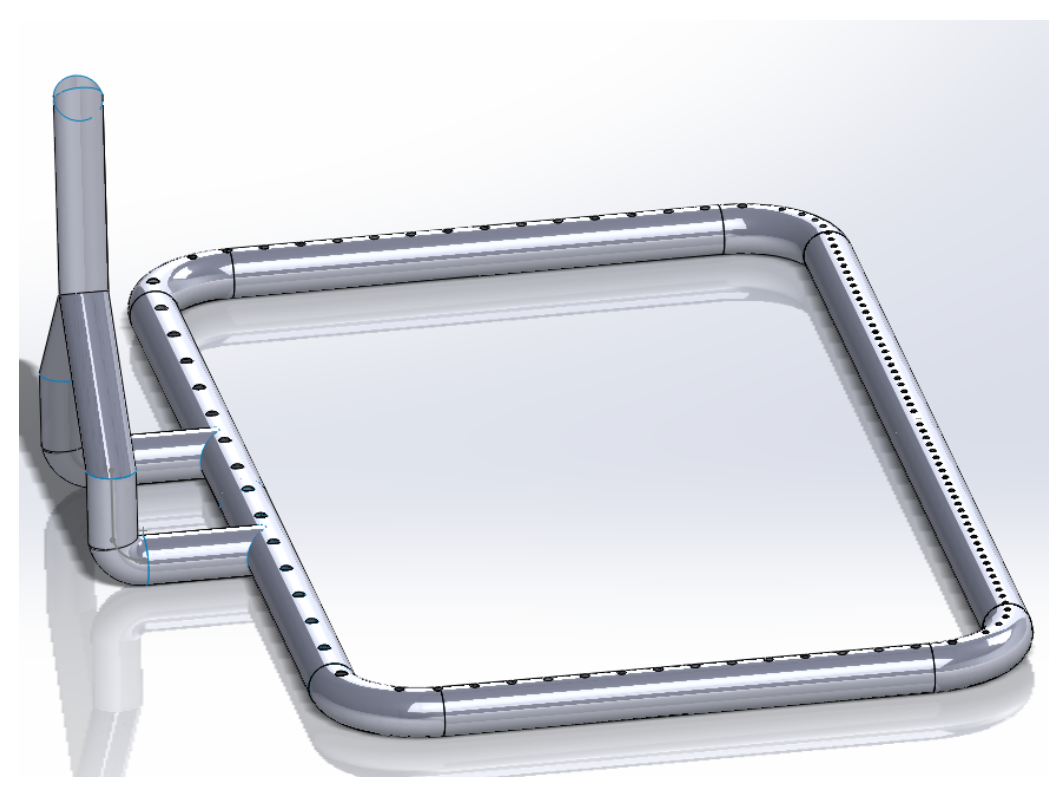

Figure 4. Downdraft system to be installed around the perimeter of the printer.

Initial tests were performed at Kent, WA facility, while the Manufacturing Demonstration Facility was being readied to accept the printer. The thermoset printer was then transferred to and installed at ORNL. Figure 5 shows how the printer was shipped from Kent, WA to Knoxville, TN. There was no damage during transportation and the printer worked after assembly. Figure 6 shows installation of the equipment at ORNL's Manufacturing Demonstration Facility (MDF).

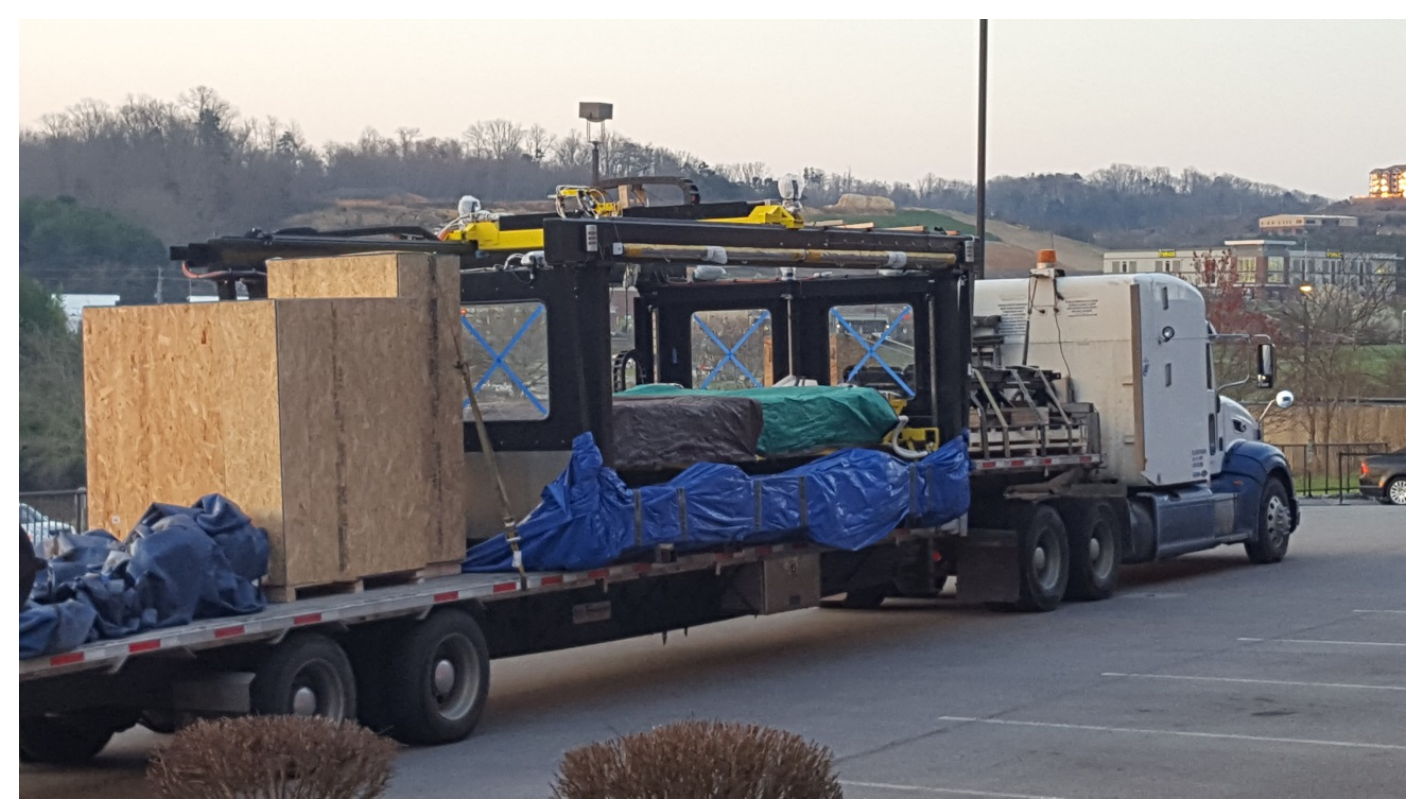

Figure 5. Thermoset printer shipped from Kent, WA, to Knoxville, TN 


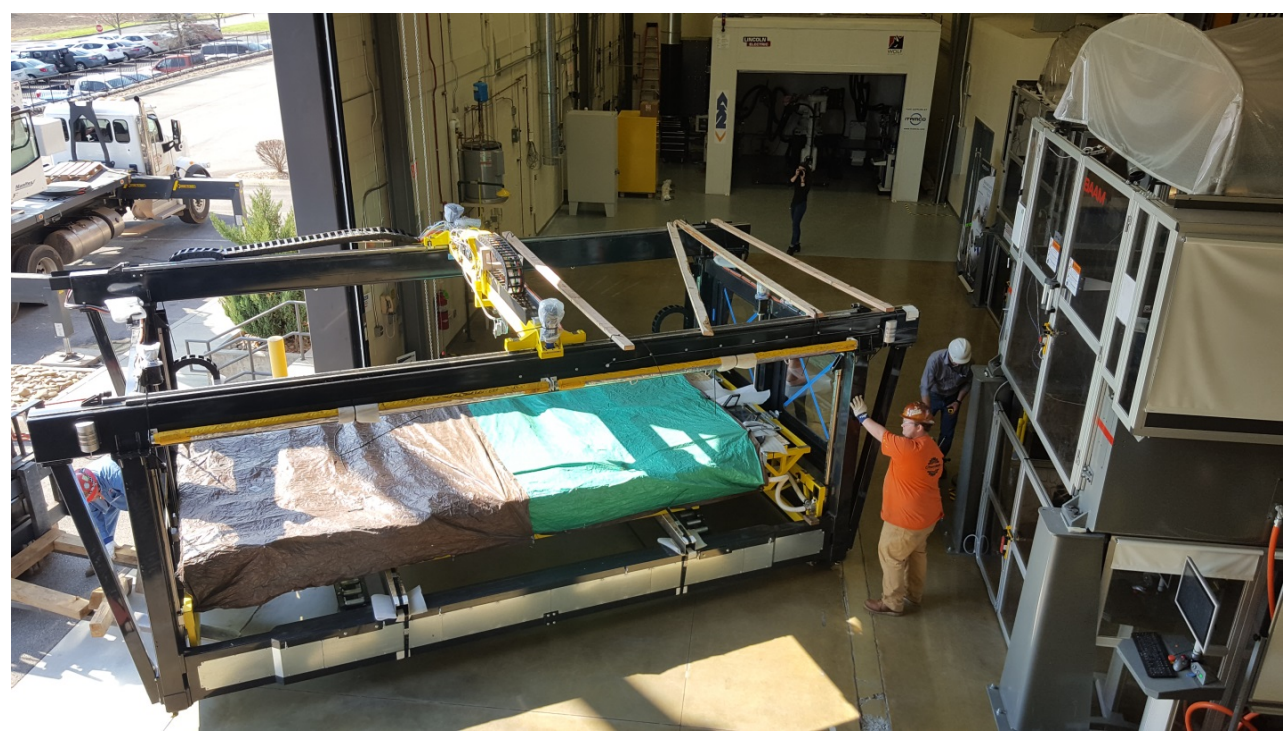

Figure 6. Installation of thermoset printer at the Manufacturing Demonstration Facility of ORNL.

Figure 7 shows downdraft setup during installation with exhaust piping visible by the wall behind the printer. This piping leads to an explosion proof vent at the roof of the facility. Additional safety features included installation of enclosures for the printing area and loading area, setup of infrared system for exotherm monitoring and testing of light curtains.

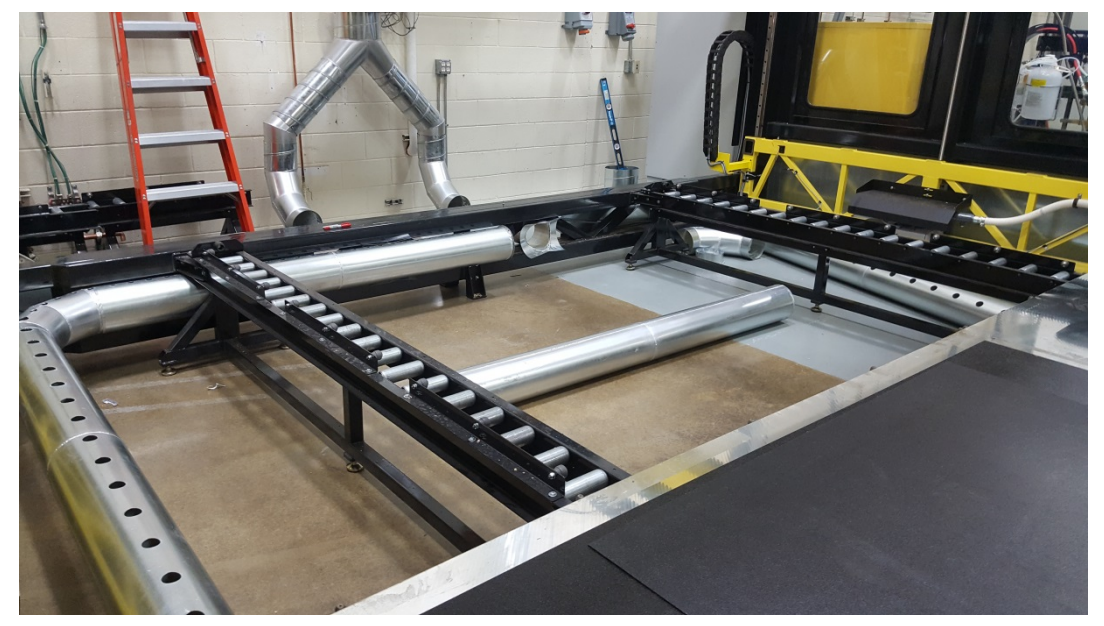

Figure 7. Downdraft system and rollers for a removable bed.

Operation of large scale printers requires often time consuming pre- and post- processing operations. The printer is typically idle during these operations, leading to sub-optimal use of capital and increased production costs associated with large scale additive manufacturing. To alleviate this problem, the printer was designed with a removable bed as well as segments of removable bed. The printer with the bed removed from the gantry and exposed rollers are shown in Figure 7. Figure 8 shows the final configuration of the printer. 


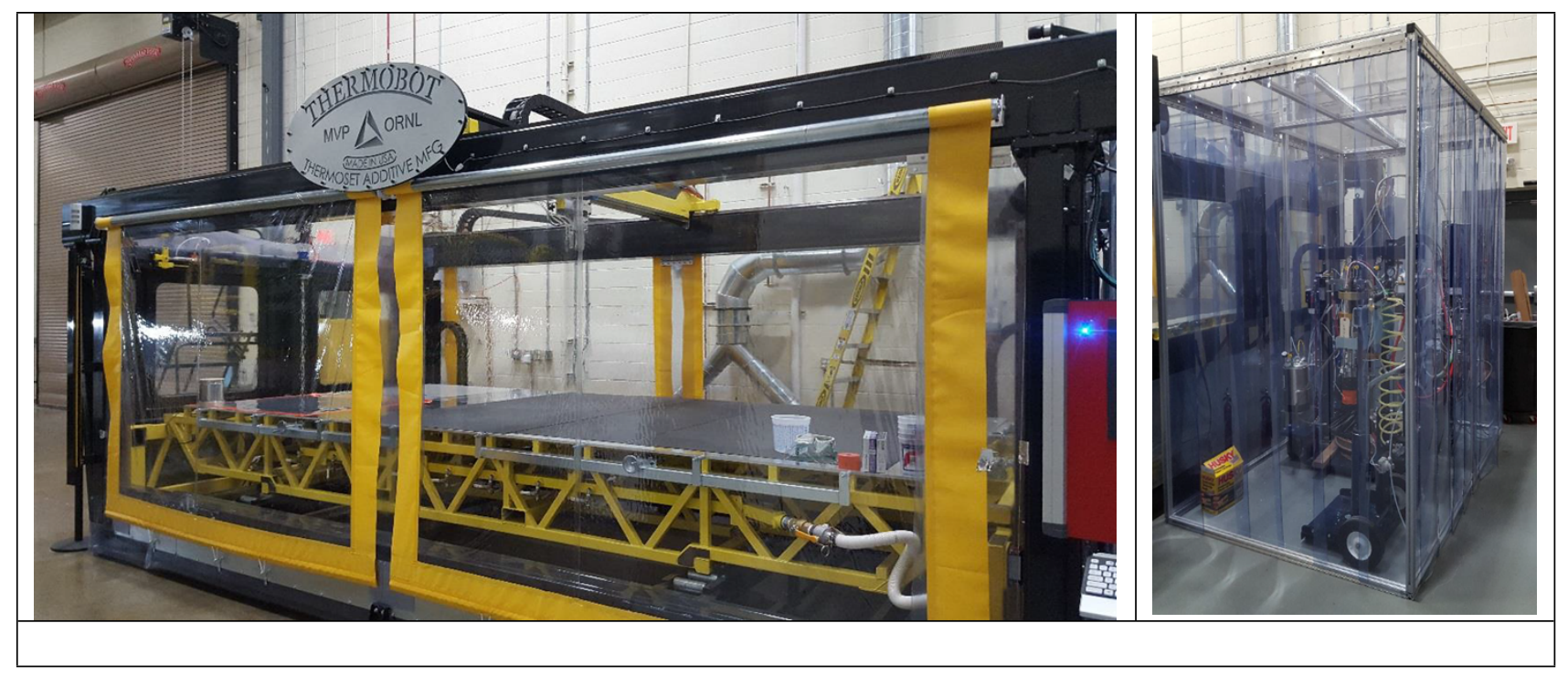

Figure 8. Final configuration of printer gantry and loading station.

A ribbon cutting ceremony was performed at MDF to acknowledge the achievement of the team in this project. Figure 9 shows how the event was attended by 30+ MVP employees as well as ORNL staff. Remarks were given by MVP CEO Bob Vanderhoff and ORNL associate laboratory director Moe Khaleel. The event was accompanied by a press release:

http://www.mvpind.com/announcements/partnership-ornl-mvp-releases-first-commerciallyavailable-medium-large-scale-thermoset-printer-2/

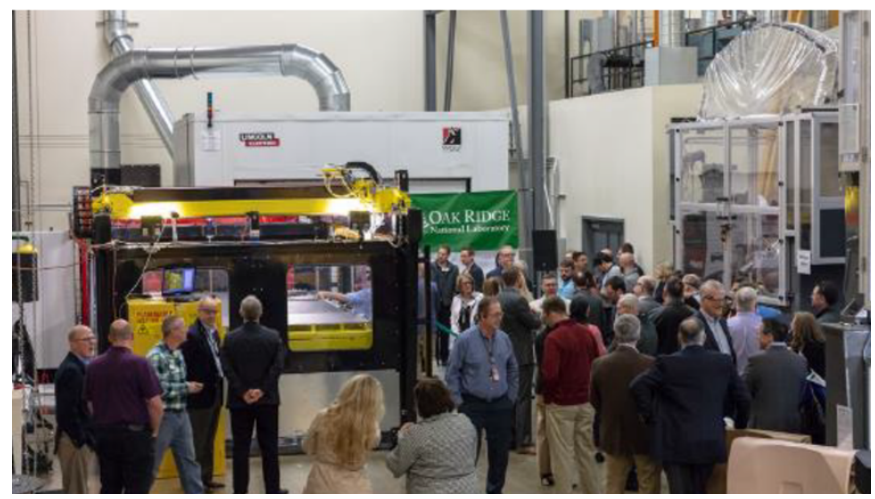

Figure 9. Ribbon cutting ceremony for thermoset printer at ORNL.

\subsubsection{Material and process parameter development for core printing}

ORNL and MVP staff have been gaining experience with operation and maintenance of the machine as well as with behavior of materials being printed in the system throughout the project. One of the major concerns for printing of large objects was an excessive heat excursion during or after printing, since thermoset materials experience exotherm during reaction. To this end, infrared cameras were installed in the printer to collect exotherm data for material development as well as for safety monitoring. Figure 10 shows a permanently 
installed infrared camera and Figure 11 shows exotherm observed in deposited material during printing of fast reacting polymer.

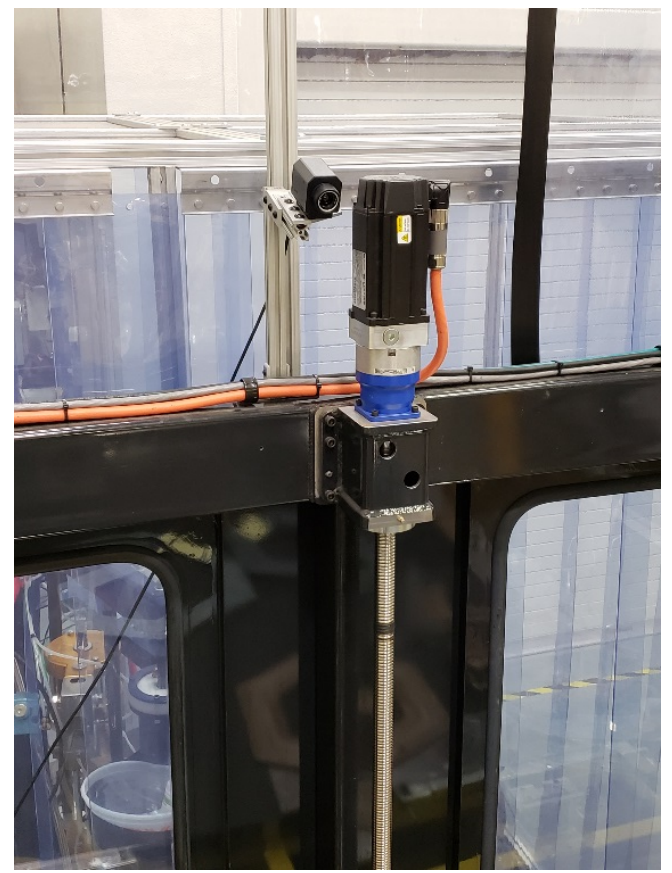

Figure 10. Permanently installed infrared camera.

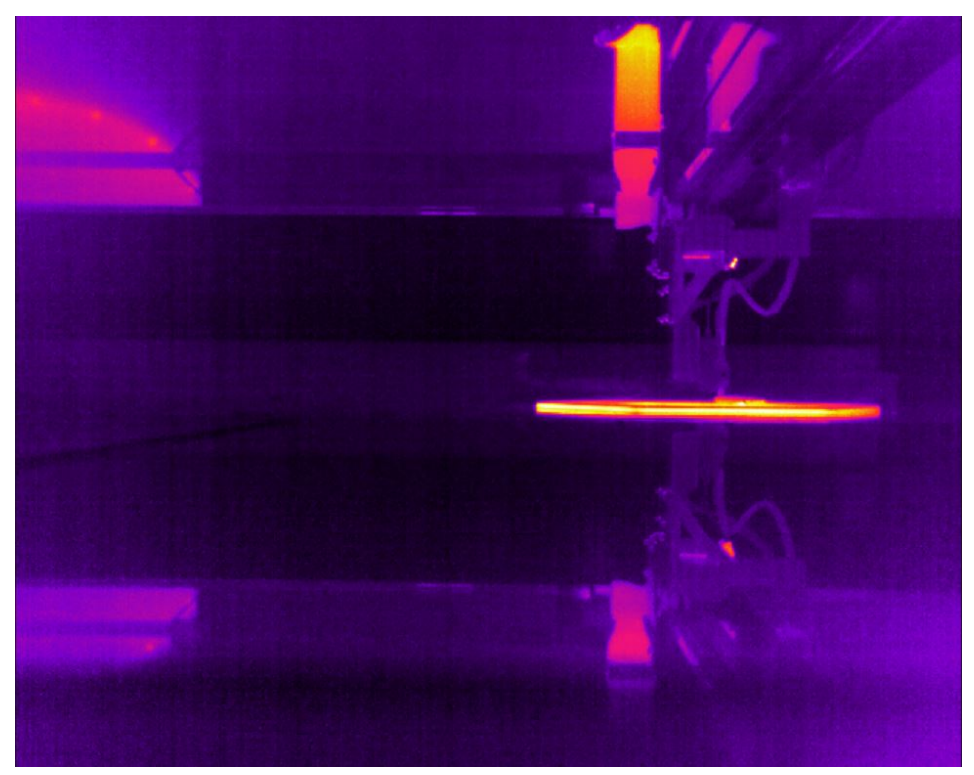

Figure 11. Infrared image shows exotherm in deposited material.

There were multitude of test trials performed with material compositions varying in viscosity, cure and gel time. Primary focus was placed on polyester and vinylester compositions due to expected low cost of printable materials as well as good mechanical properties. After gaining experience and comfort with the printer and the materials, trials on the full bed were performed. Figure 12 shows a full bed print that was performed to monitor 
styrene emissions in the vicinity of the printer to assure compliance with health and safety regulations. Typical monitoring station is shown in Figure 13.

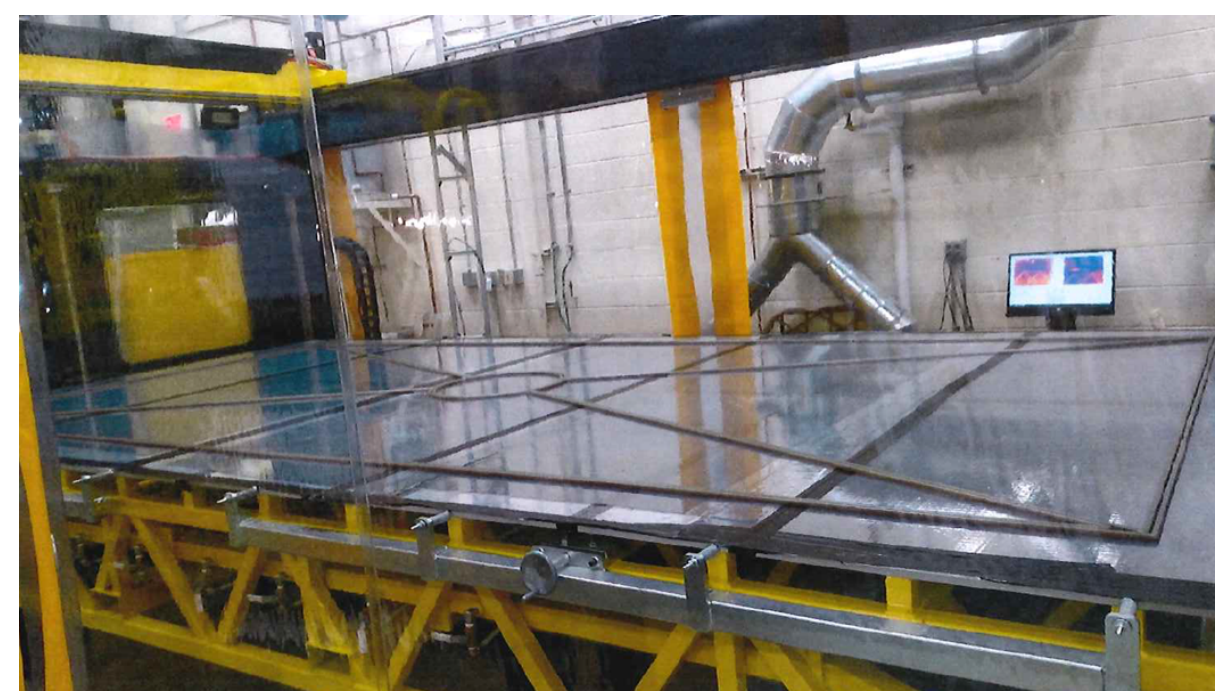

Figure 12. MVP printer enclosure, light curtain and fume isolation.

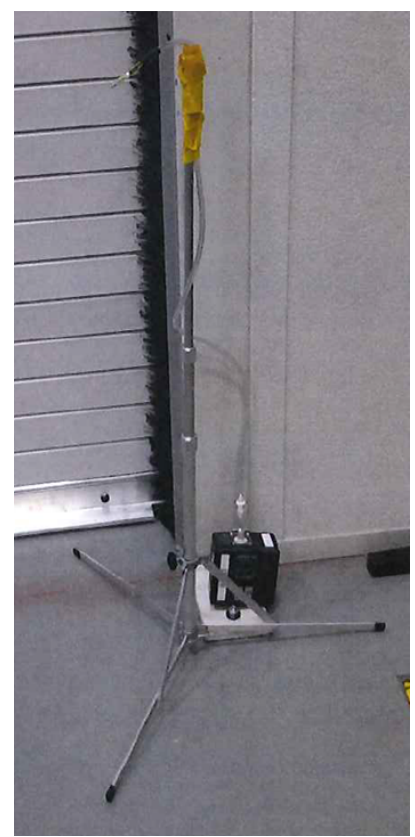

Figure 13. MVP printer loading area enclosure and ventilation.

Total of twelve locations were sampled with all result falling well below Office of Safety and Health Administration (OSHA) limits. Lab results are shown in Table 1. Additional evaluation of health and safety hazards was performed for initiators that allows faster reaction with polyester and vinylester pastes as well as replicate measurements of styrene emissions.

Table 1. Results from styrene emission monitoring. 


\begin{tabular}{|c|c|c|c|c|c|c|}
\hline Sample ID & Date & Sample detail & Type & TWA/Result & $\mathrm{OEL}$ & Unit \\
\hline SID11208-01 & 10 SEP 2018 & NTRC-2 FIRST 163 & GENERAL AREA STYRENE, MONOMER & 0.27959 & 20 & PPM \\
\hline SID11208-02 & 10 SEP 2018 & NTRC-2 FIRST 163 & GENERAL AREA STYRENE, MONOMER & $<0.1512$ & 40 & PPM \\
\hline SID11208-03 & 10 SEP 2018 & NTRC-2 FIRST 163 & GENERAL AREA STYRENE, MONOMER & 0.1942 & 40 & PPM \\
\hline SID11208-05 & 10 SEP 2018 & NTRC-2 FIRST 163 & GENERAL AREA STYRENE, MONOMER & 0.77679 & 40 & PPM \\
\hline SID11208-04 & 10SEP 2018 & NTRC-2 FIRST 163 & GENERAL AREA STYRENE, MONOMER & 0.54431 & 40 & PPM \\
\hline SID11208-08 & 10 SEP 2018 & NTRC-2 FIRST 163 & GENERAL AREA STYRENE, MONOMER & $<2$ & 20 & PPM \\
\hline SID11208-09 & 10SEP 2018 & NTRC-2 FIRST 163 & GENERAL AREA STYRENE, MONOMER & $<2$ & 20 & PPM \\
\hline SID11208-10 & 10 SEP 2018 & NTRC-2 FIRST 163 & GENERAL AREA STYRENE, MONOMER & $<2$ & 20 & PPM \\
\hline SID11208-11 & 10 SEP 2018 & NTRC-2 FIRST 163 & GENERAL AREA STYRENE, MONOMER & 2 & 20 & PPM \\
\hline SID11208-12 & 10 SEP 2018 & NTRC-2 FIRST 163 & GENERAL AREA STYRENE, MONOMER & 2 & 20 & PPM \\
\hline
\end{tabular}

Initial material tests consisted of printing simple structures such as hexagons (Figure 14) or regular shapes with rectangular lattice infill (Figure 15).

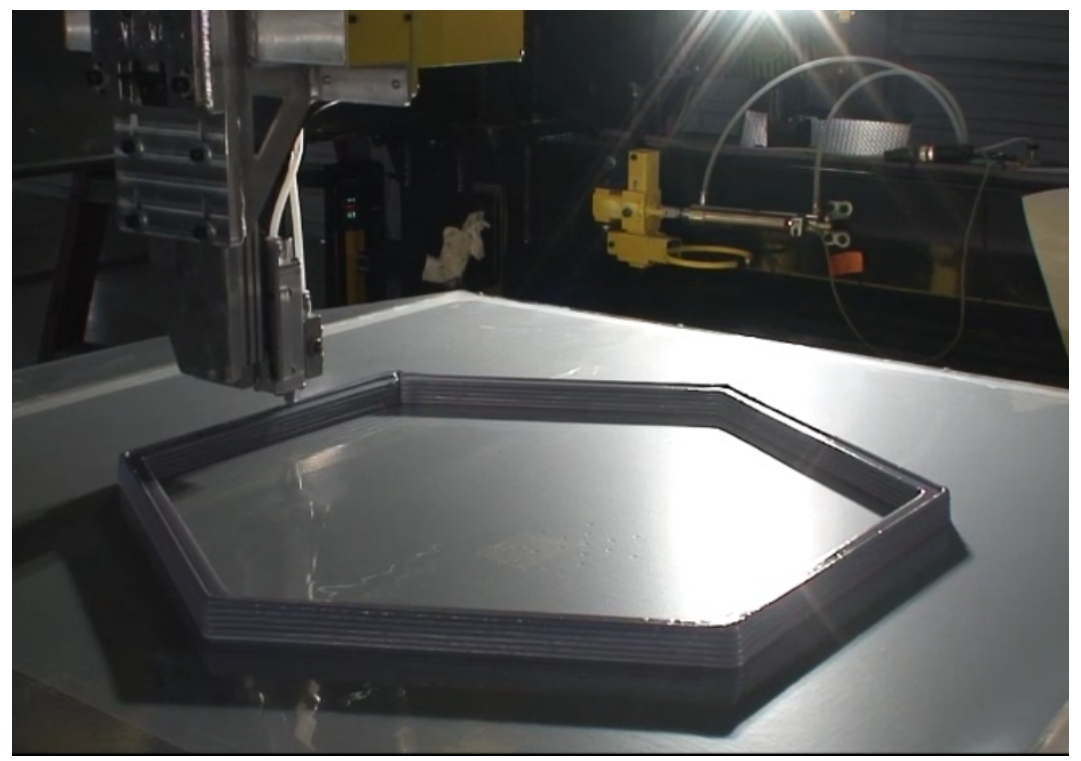

Figure 14. Initial print test of multi-layer hexagon.

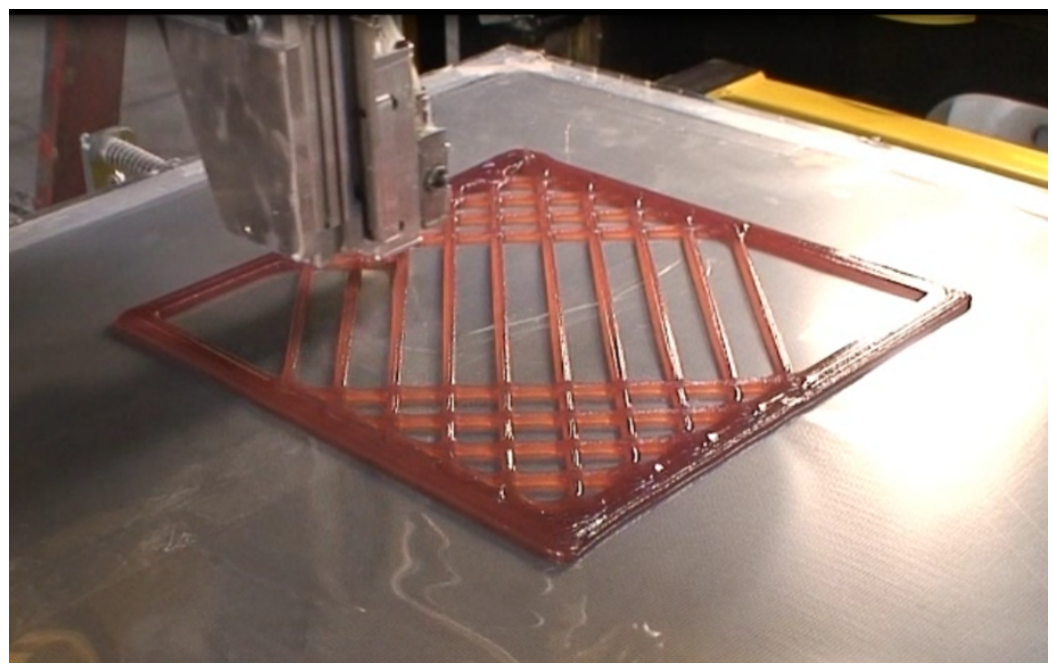

Figure 15. Print test of a square with rectangular lattice infill.

As noted previously, compositions with short and long gel time were tested. Figure 16 shows 
progressive gelling of material with fast reaction kinetics. Note the difference between the color of the top layer and previous layers. Multiple material compositions with gel time exceeding twenty minutes were tested. It is apparent from Figure 17 that long gel time material compositions can support several layers without the necessity to rely on gelling and curing of the polymer during print. This fact bodes well for low residual stresses and good cross-linking between layers for materials printed in this system.

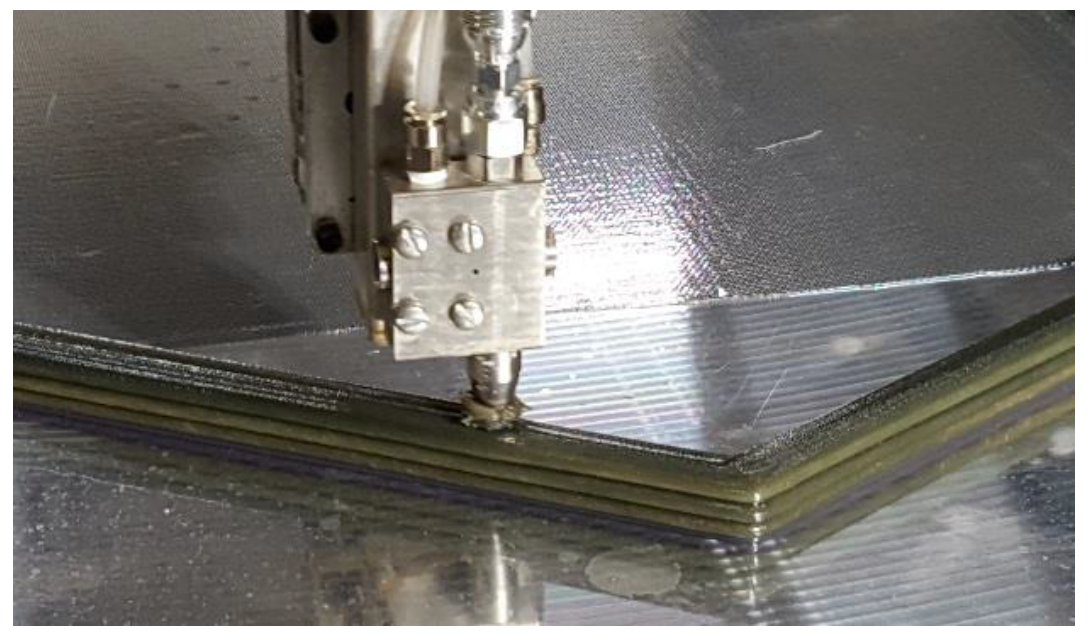

Figure 16. Progressive curing of thermoset material during printing.

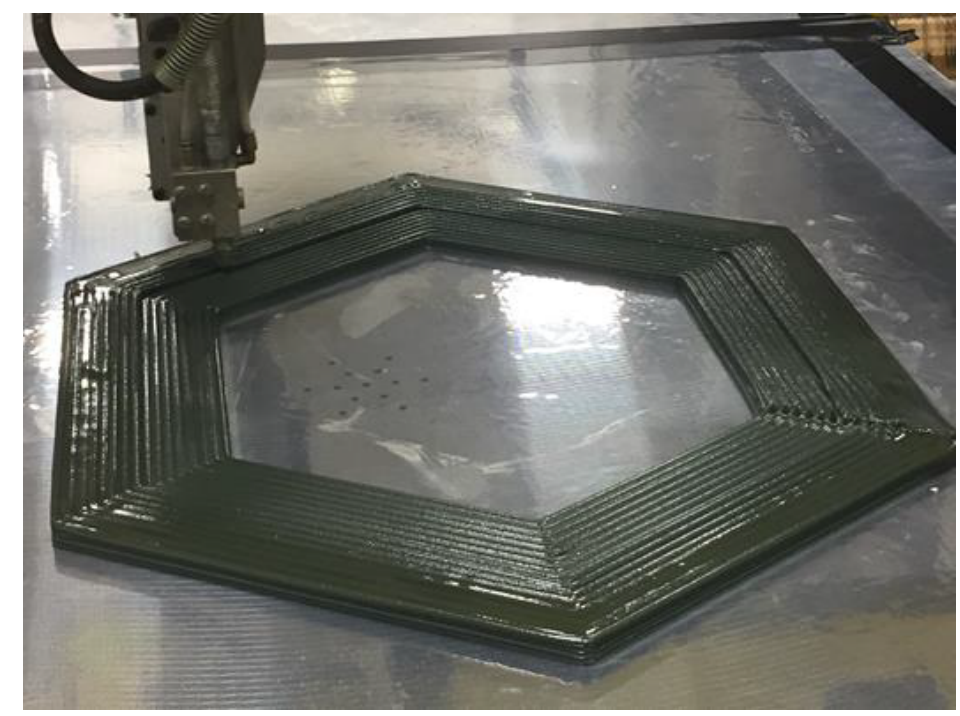

Figure 17. Large volume hexagon printed with long gel time material.

Figure 17 also illustrates testing that was performed during this project to establish temperature and cure profiles on volume/geometry of printed part. Unlike thermoplastic material additive manufacturing, where average bulk material temperature only decreases after deposition, in thermoset additive manufacturing the temperature of material typically increases after deposition as illustrated in Figure 18. The increase in temperature is driven by material composition and deposition rate as well as volume and geometry of printed part. 


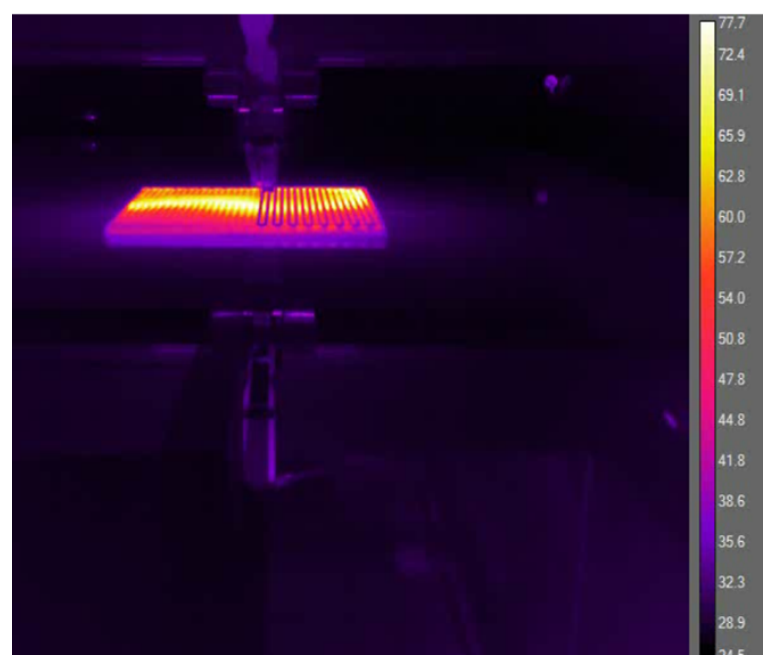

Figure 18. Infrared image of thermoset material deposition showing elevated temperature of reacting polymer.

Material development focused on arriving at printable compositions allowing generation of variable density lattice structures. To this end, compositions with only modest build height were sufficient to demonstrate the power of this technology. Figure 19 shows an example variable density lattice test article printed during material development.

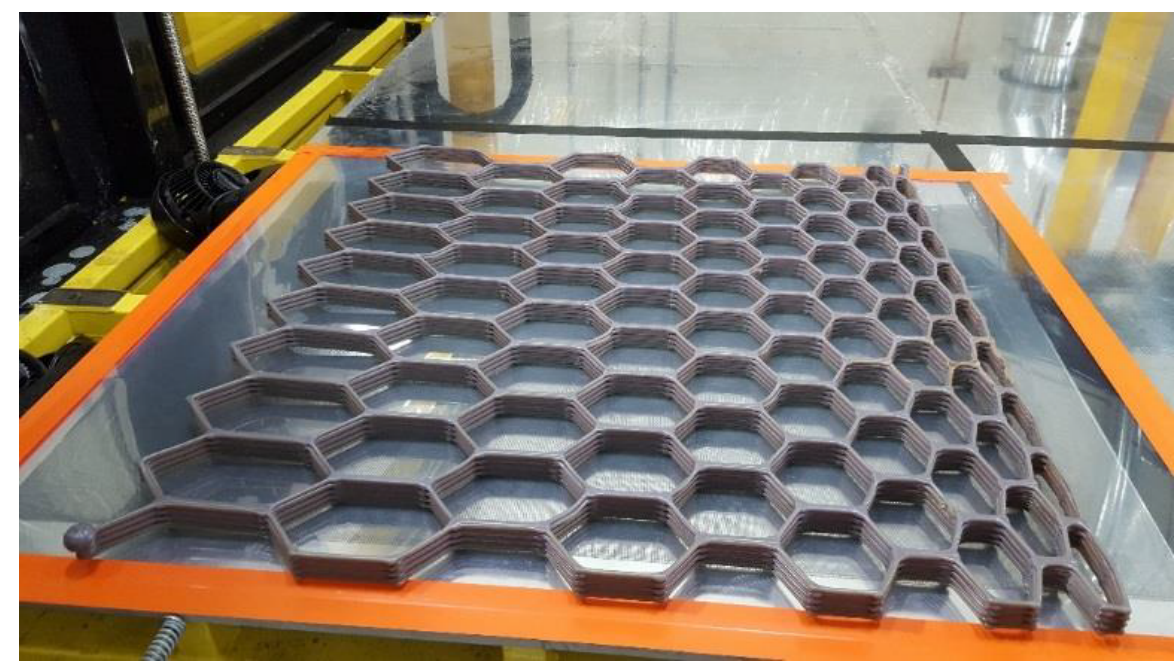

Figure 19. Example variable density lattice printed during material development.

\subsubsection{Demonstration of composite core printing}

Being able to print materials on the full bed consistently allowed the team to start generating full scale demonstration articles. Figure 20 shows a variable density lattice structure printed in preparation for Composites and Advanced Materials Expo (CAMX), which was selected as the venue for public display of the technology. This conference offered the opportunity to present our work to the largest possible target audience as CAMX is the largest composites trade show in the United States. 


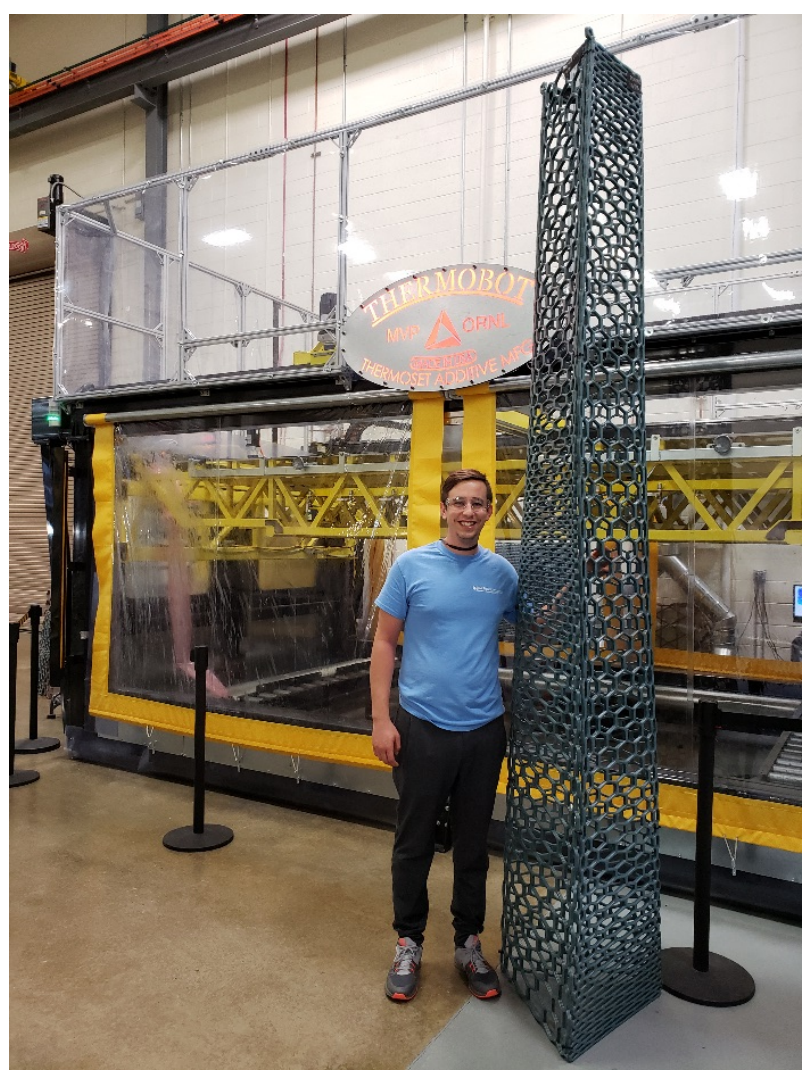

Figure 20. Variable density lattice structure printed on MVP machine.

The team was nominated for two awards and won one award at this conference. Figure 21 shows a structure printed for CAMX award display space, where the team was a finalist for the Unsurpassed Innovation Award. This printed structure resembles internal structure of a boat.

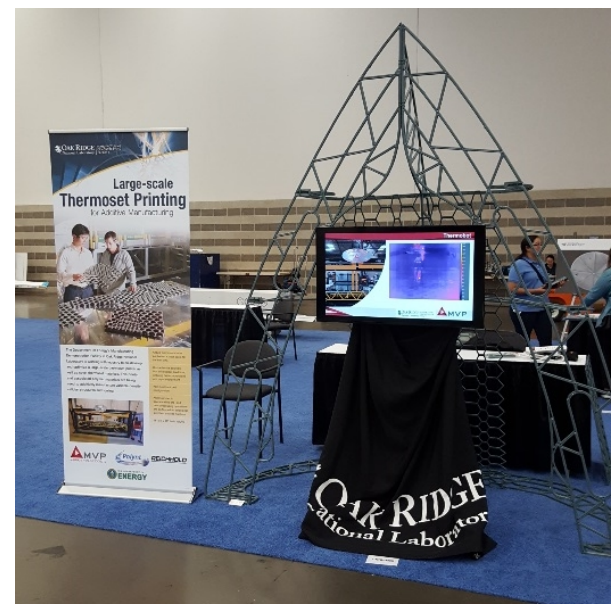

Figure 21. CAMX booth display.

Figure 22 shows display in space reserved for Award for Composites Excellence (ACE), 
where the team won ACE in the Market Growth Category. In this display, we are showing the ability to print large lattice structures and use them as a core in a sandwich structure. In particular, the team has manufactured a car hood with integrated 3D printed core. Detail of this hood is shown in Figure 23.

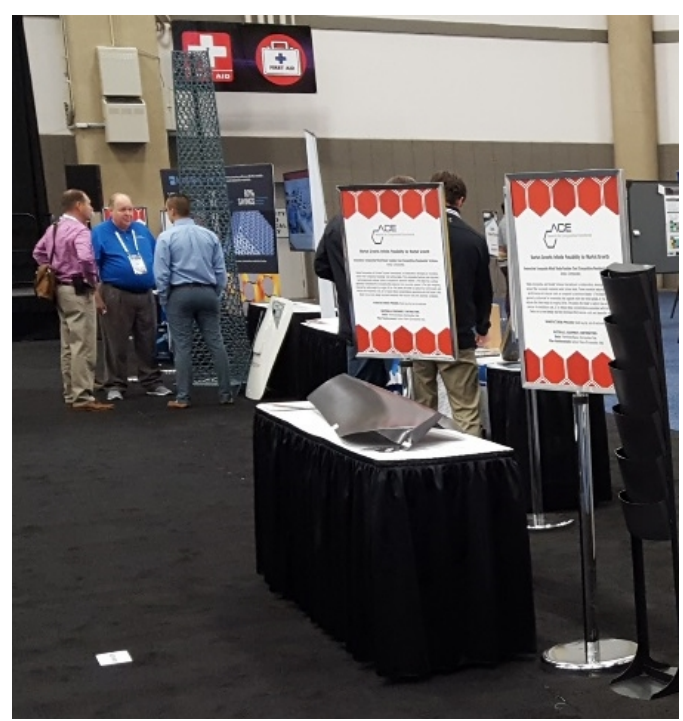

Figure 22. Award for Composites Excellence booth.

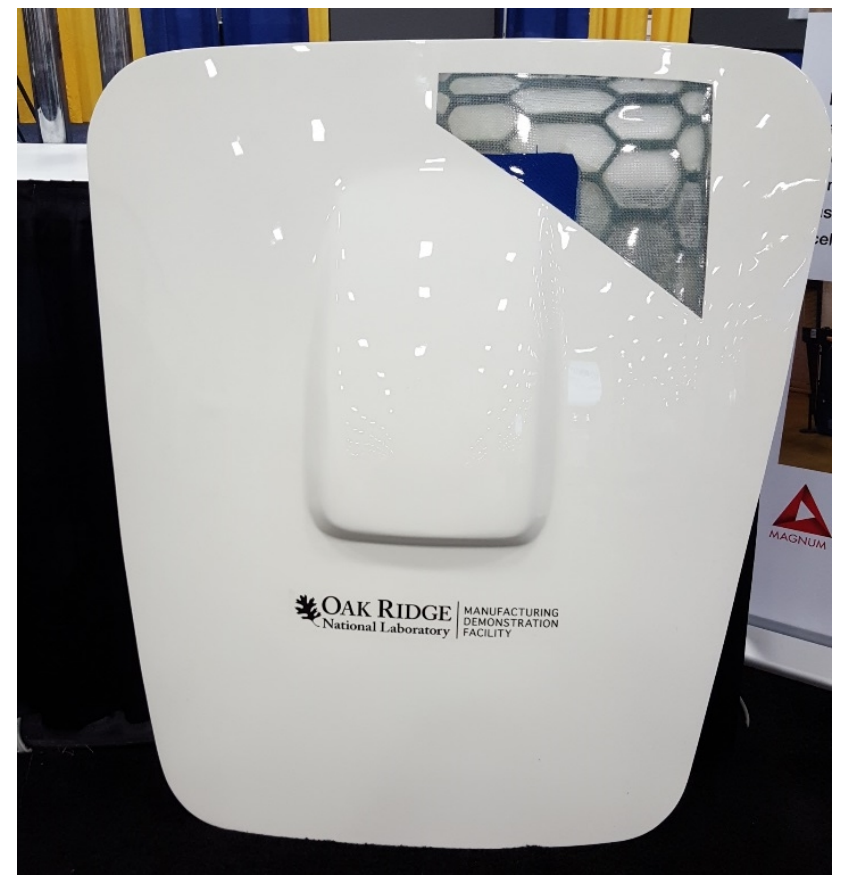

Figure 23. Car hood with thermoset 3D printed variable density core. 


\subsection{IMPACTS}

The team has developed first in the world mid/large scale 3D printer capable of depositing thermoset materials. All project tasks and milestones were completed. Materials and processing parameters were developed to allow full scale demonstration of this technology. The team won Award for Composites Excellence in the Market Growth Category at the Composites and Advanced Materials Expo, which is the largest composites trade show in the United States. MVP is currently entertaining orders for this printer.

\subsubsection{Subject Inventions}

Two invention disclosures were filed as a result of this project.

ID201904344 - Increased material flow throughput in large scale additive manufacturing through movable segmented build platform.

ID16358768 - Pumping System and Method for 3D Printing

\subsubsection{Publications}

The development of the thermoset printer was presented at multiple venues and published in conference proceedings (LARGE-SCALE ADDITIVE MANUFACTURING WITH REACTIVE POLYMERS, John Lindahl et.al., CAMX Conference Proceedings. Dallas, TX, October 15-18, 2018. CAMX).

\subsection{CONCLUSIONS}

MVP and ORNL have developed breakthrough technology allowing additive manufacturing of thermoset material on industrial scale. All tasks and milestones of this project were achieved.

\section{MAGNUM VENUS PRODUCTS COMPANY BACKGROUND}

Magnum Venus Products is the premiere manufacturer of composite application equipment and is known for its innovation and high-quality fluid handling equipment and products. MVP serves manufacturers in industries including automotive, aerospace, transportation, marine, railway, oil and gas, and wind energy. Magnum Venus Products has over 70 years of experience delivering highly-customized solutions to its customers. 